\title{
Increasing Usage of ESL Instructional Practices in a Rural County
}

\section{Elementary School}

\author{
John J. Hoover \\ Julia S. Sarris \\ Raymond Hill \\ University of Colorado
}

The study setting is one elementary school located in a remote rural county school district in a mountain western state. Implementing a specific set of procedures, ESL Instructional Improvement Process, educators examined and increased use of research-based ESL instructional practices in the education of English learners (ELs). A key feature of the piloted process is educator self-assessment of instructional practices, resulting in the development of workshop sessions and action items, and completion of classroom observations. Researchers found that the process proved effective in increasing rural educators' knowledge and application of ESL best practices. Self-assessment was highly effective in helping educators examine existing instructional practices, leading to relevant workshop sessions and classroom implementation of ESL action items. Numerous examples of the use of research-based ESL instructional practices as a result of this project are provided, along with suggestions for further research to improve the education of ELs in rural county schools.

\section{Key Words: rural education, ESL instruction, educator self-assessment, professional development}

The intersection of increased numbers of English learners (ELs) and the challenge of providing contemporary professional development to acquire needed instructional practices to educate these learners characterizes a significant need in rural county schools. The importance of providing culturally relevant and responsive instruction in diverse teaching and learning environments is well documented in the literature (see Brown \& Doolittle, 2008; Garcia \& Ortiz, 2006; Ladson-Billings, 2001, 1994; Ortiz \& Artiles, 2010). However, delivering quality instruction to ELs assumes an added dimension in rural schools due to limited resources and difficult-to-obtain professional development (Burton \& Johnson, 2010; Wenger, Dinsmore, \& Villagómez, 2012).

Specifically, the increase of ELs in rural educational communities (Wenger \& Dinsmore, 2005) continues to challenge educators in their delivery of contemporary instructional practices to students in the process of acquiring English as a second language (ESL). Though a variety of models exist to improve teacher practice, the use of guided teacher self-assessment supported by coaching and workshops provides promise as an effective professional development framework (Avalos, 2011; Ross \& Bruce, 2007). Teacher self-assessments reflect a more relevant educational context by initially drawing on their perspectives, which in turn, frames coaching and workshop sessions. This article summarizes research designed to increase teacher use of ESL instructional practices with ELs in a K-5 elementary school in a remote rural county school district. The researchers in this project are university faculty with extensive experiences in educator preparation for work with English learners, with and without learning disabilities.

\section{Literature Review}

Sorrells, Webb-Johnson and Townsend (2004) found that general and special educators' misperceptions about diversity and education contribute to a school's inability to meet cultural and linguistic needs in the classroom. Potential misperceptions may be alleviated through culturally responsive instruction that supports sufficient opportunities to learn for all ELs (Herrera \& Murry, 2005); thereby structuring an educational framework that assists educators to avoid misinterpreting learning differences as learning disabilities (Ortiz \& Artiles, 2010). However, sufficient opportunities to learn for ELs is only possible if classroom teachers possess contemporary research-based ESL 
instructional practices, which may be difficult for many rural school educators to obtain due to unique challenges as summarized below.

\section{Contemporary Skills Development in Rural Schools}

Dunn, Cole, and Estrada (2009) found that teachers in rural schools often experience fewer educational supports for curriculum delivery and student assessment than educators in other geographic areas. In addition, limited resources, excessive travel expenses, and more limited associations with institutions of higher education frequently exist due to remote school locations (Clarke \& Wildy, 2011). Regarding teacher recruitment, Robinson, Bursuck, and Sinclair (2013) noted securing highly qualified teachers in rural areas is difficult due to lower salaries and limited social and cultural opportunities. As a result, the development of strong candidate pools for critical positions, such as ESL prepared teachers or intervention specialists, in rural schools may be compromised.

Stockard (2011) wrote that "reviews of research on rural education suggest that identifying ways to help rural schools improve teachers' pedagogical skills should be a high priority" (p. 1), including greater emphasis on instructional practices to improve students' learning opportunities to strengthen achievement (Arnold, Newman, Gaddy, \& Dean, 2005). In reference to professional development, Basil (2011) found that rural educators identified the characteristics of quality, relevance and practicality as essential features. Relative to the topic of this study (i.e., implementing contemporary ESL instruction), the improvement of teacher skills is directly emphasized through development of ESL best practices for educating the ever-increasing population of ELs in rural county elementary school classrooms.

\section{Educational Practice and English Learners}

Effective teaching standards emphasized through national and state accreditation organizations (e.g., Council for the Accreditation of Educator Preparation-CAEP) describe expectations for research-based knowledge and skills important to teachers' continued success in the classroom. While research indicates some general education practices are effective with English learners (ELs), it also signals the need for teachers to make appropriate pedagogical modifications to account for differences in language proficiency and cultural diversity (August, Shanahan \& Shanahan, 2006; Goldenberg,
2008). If modifications are not properly designed and implemented, the education of ELs in the general education curriculum may lead to inadequate progress (Garcia \& Ortiz, 2006).

As a result, high quality instruction through implementation of research-based instructional practices is essential to effectively educate ELs in culturally and linguistically responsive ways, which include the structuring of learning that builds on students' diverse backgrounds, interests, and home/community teachings (Gutierrez \& Rogoff, 2003). According to Hoover, Klingner, Baca, and Patton (2008), the proper interpretation of cultural and linguistic influences in the classroom requires educators to acquire an understanding of the differences between cultural/linguistic and disability behaviors, and utilize this knowledge to deliver appropriate instruction. From analysis of the literature, at least three conditions may exist within rural schools that potentially threaten implementation of effective instruction for ELs:

1. Limited resources and supports to assist teachers to know about contemporary ESL instructional best practices;

2. Lack of contemporary knowledge about the role of cultural and linguistic responsive instruction in teaching and learning for diverse learners; and,

3. Lack of safeguards preventing the misinterpretation of diverse learning differences as learning disabilities thereby directly impacting classroom instructional adjustments and decision-making.

Addressing these three conditions requires training and support by bringing contemporary research-based practices to rural communities, beginning with an examination of current strengths and needs from the perspectives of those most directly responsible for delivering ESL instruction: the classroom teacher.

\section{Role of Teacher Self-Assessment in Instructional Improvements}

Research has long supported the value of teacher self-assessment toward implementing best practices to improve student achievement. "When an educator engages in meaningful reflection, conclusions can be drawn that provide insight for future instruction" (Lupinsky, Jenkins, Beard, \& Jones, 2012, p. 81). Ross and Bruce (2007) focused on self-assessments' contributions 'to teachers' beliefs about their ability to bring about student learning" (p. 4). They found that self-assessment, guided by a tool of best practices, supported a teacher's inclusion of those best practices. 
Additionally, incorporation of best practices in the classroom was found to assist in changing and clarifying teachers' definition of teaching excellence.

Based on a review of literature, Avalos (2011) wrote that use of a self-assessment tool reinforces "the value of existing practices and strengthened beliefs about competence, but also provided information for improvement" (p. 6). Providing a framework and structured guidance in selfassessment is considered essential to producing teacher change (McCombs, 2003). Additionally, a teaching practices survey is valuable in triangulating other forms of data collection, such as interviews, observations and workshop sessions (Schmidt, Baran, Thompson, Koehler, Mishra, \& Shin, 2009). Overall, recent literature supports the value of teacher selfassessment, especially when coupled with a formal tool to guide the process within an established set of parameters.

\section{Purpose and Significance of Study}

Grounded in teacher self-assessment, researchers piloted a process designed to provide rural county educators with (a) informed and relevant workshop sessions; (b) development of action items to increase use of ESL practices in classroom instruction for ELs; (c) structured feedback based on classroom observations of identified action items. One research question guided this study: What effect does a professional development process, grounded in educator self-assessment, have on identifying and improving use of ESL instructional practices when teaching ELs in a rural school setting? To respond to this question a professional development structure referred to as the ESL Instructional Improvement Process was piloted. This process, illustrated in Figure 1, includes five research-based professional development components (Basil, 2011; Borko, 2004; Cornett \& Knight, 2009; Knight, 2012; Kretlow \& Bartholomew, 2010; Kretlow, Cooke \& Wood, 2011; Teemant, 2013), designed to improve educators' use of research-based ESL practices in the education of ELs.

The emphasis of incorporating essential ESL practices in teaching and learning is critical to the education of ELs given that approximately $75 \%$ of school programs for ELs adhere to an ESL model (Kindler, 2002), rather than bilingual or dual language models. Project is significant in that it addresses the two issues of improving teachers' contemporary skills (i.e., ESL best practices), along with relevant professional development to educators in rural county schools (i.e., teacher self-assessment to improve ESL instructional support).

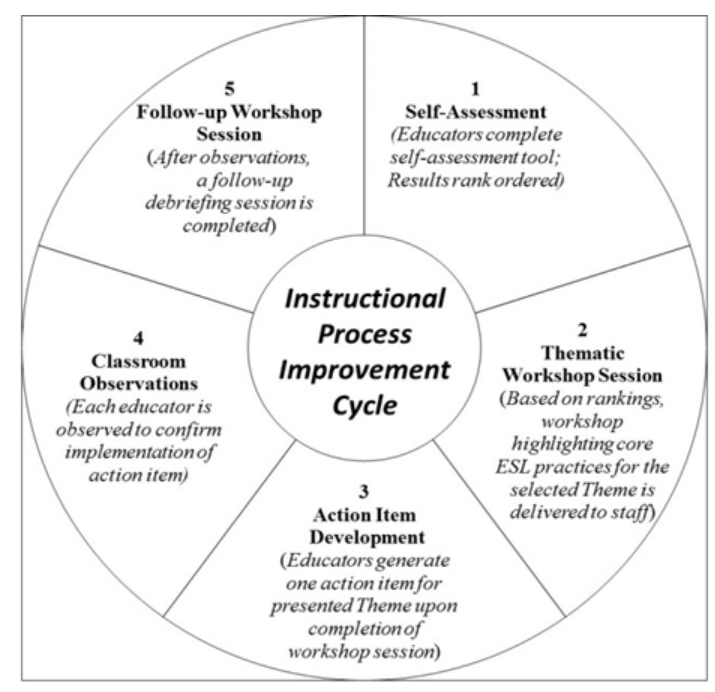

Figure 1. ESL instructional improvement process.

\section{Study Methods}

The study, completed during the 2013-14 academic school year, employs qualitative methodology (Creswell, 2011; Glesne, 2005) to examine effects of the piloted ESL Instructional Improvement Process on educators' use of researchbased ESL instructional practices in teaching. Sources of evidence to examine project effects include self-assessment, interviews, and classroom observations to be discussed in detail in a subsequent section. Data analyses included thematic analysis of interview responses and classroom observational narrative summaries to identify common ESL features and instructional practices. Also, mean CEIP scores of self-assessment ratings were calculated and rank-ordered from lowest to highest to determine which ESL themes are perceived by participants to be most and least emphasized in classroom instruction, thereby guiding the order of coverage in workshop sessions and associated supports.

\section{Setting and Participants}

The context of our teacher ESL instructional improvement pilot project is one elementary school with a student population of approximately 300 learners located in a medium sized remote rural school district in a mountain western state. The district and school settings include $37 \%$ and $50 \%$ ELs, respectively. The district covers 2,500 square miles of rural mountain terrain in the central Rockies. The district has seen a $44 \%$ increase in linguistically diverse learners over the past several years, with an overrepresentation of ELs in special education (i.e., $49 \%$ of special education students are ELs; $37 \%$ of 
the district population is ELs). Project participants included the staff of 20 educators (i.e., classroom teachers, principal, master teacher, support educators) in the kindergarten through fifth grade school site. Participants ranged in degree levels and years of experience completed both in and out of the district, with many holding a master's degree and several years teaching experience.

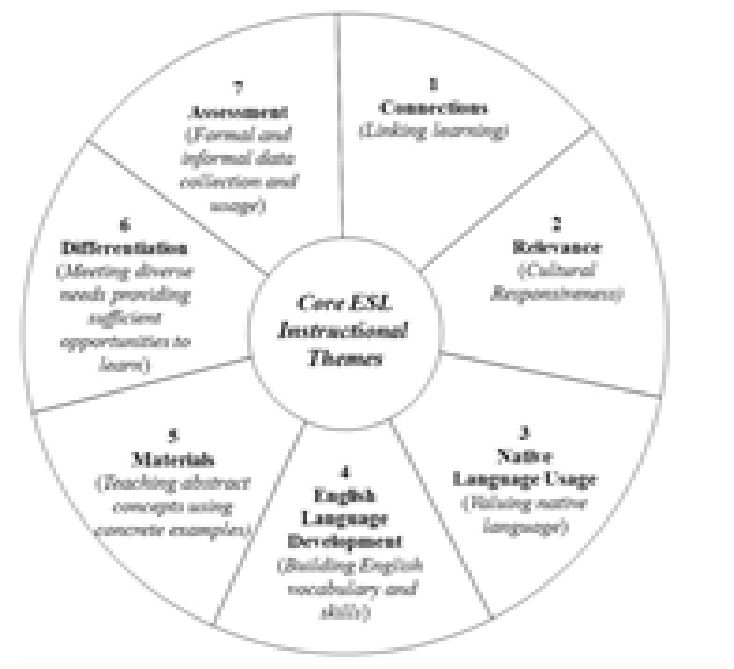

Figure 2. Core themes for implementing researchbased ESL practices.

A university-school partnership provided the foundation for this project. The school staff expressed a desire to engage in self-examination of classroom teaching practices for the purpose of improving the instruction of ELs. The researchers recently developed a process for identifying and improving ESL teaching skills, which included use of a research-based self-assessment ESL instructional practices guide. Based on joint planning that built on the established partnership, the project summarized in this article was developed, implemented, and evaluated.

\section{Project Protocol: Core ESL Instructional Practices (CEIP)}

The selected project protocol was a researchbased self-assessment tool titled the Core ESL Instructional Practices (CEIP) guide (Hoover, Hopewell, \& Sarris, 2014). The CEIP tool contains seven instructional themes, illustrated in Figure 2, considered essential to the education of ELs in today's classrooms (see August, Shanahan, \& Shanahan, 2006; Cason, 2011; Choi, 2013; Goldenberg, 2008; Herrera, \& Murry, 2005; Hopewell, 2011; O’Toole, 2010; Saunders,
Goldenberg, \& Marcelletti, 2013; Valle, Waxman, Diaz, \& Padrón, 2013).

Below are descriptions of the focus of each of the seven themes relative to the education of English learners educated within an ESL model of instruction.

\section{CEIP Theme Descriptions}

Theme 1: Connections

Items emphasize the learning of academic language for ELs, which is greatly facilitated by contextualizing academic language through connections to known content and skills (Klingner, Soltero-González \& Lesaux, 2010).

Theme 2: Relevance

Items emphasize incorporation of diverse cultures in classroom instruction by building engagement, motivation, and self-efficacy providing a relevant learning context (Gay, 2010).

Theme 3: Native Language Utilization

Items reflect use of an English learner's first language to facilitate the acquisition of English (August, Shanahan, \& Shanahan, 2006), particularly in the acquisition of reading comprehension (Hopewell, 2011).

Theme 4: English Language Development

Items reflect verbal interactions, visual supports such as word walls and sentence stems, and appropriate wait times as examples of research supported English language development practices, providing English learners opportunities to acquire and use English in the classroom (Saunders, Goldenberg, \& Marcelletti, 2013; Tharp, Doherty, Echevarria, Estrada, Goldenberg, \& Hilberg, 2004).

Theme 5: Materials

Items emphasize use of physical and visual aids to assist English learners to recognize similarities and differences, build concepts and skills, connect concrete to abstract concepts, and acquire key vocabulary (Valle, et al., 2013; Zainuddin, Yahya, Morales-Jones, \& Aziza, 2011).

Theme 6: Differentiations

Items identify numerous differentiation practices for English learners such as Scaffolded Instruction, Sheltered Instruction, Direct Instruction, and multiple classroom pairings or groupings (Herrera \& Murray, 2005). 
Theme 7: Assessment to Inform Instruction

Items emphasize the significance of attending to

both formative and summative instructional assessment tasks to gather data to provide teachers feedback to make needed instructional adjustments that are timely, specific, and constructive (Cizek, 2010; Ruiz-Primo \& Furtak, 2007).

The self-assessment tool (CEIP) contains 47 research-based ESL instructional practices developed from literature cited above grouped within the seven themes. CEIP was developed using a diverse group of K-8 teachers $(n=101)$ who taught ESL in urban and rural schools. Development included use of expert reviews, participant interviews, focus groups, and two pilot administrations, which inform the reliability and validity of the measure. Internal consistency coefficient (i.e., Cronbach's Alpha) yielded greater than .90 based on two separate pilot occasions, indicating a reliable, internally consistent tool for use by classroom teachers.

Validity of the instructional practices was determined by means of a multi-phase systematic process that ensured face, construct, and content validity. The research team first conducted a thorough review of the extant literature concerning best/effective practices in the teaching of English learners. Both theoretical and empirical research was examined and synthesized; a synthesis that grounded the CEIP firmly in the literature, informed the first iteration of the CEIP, and contributed to establishing content and construct validity. Next, the research team recruited four Ph.D. students and five K-5 educators to participate in cognitive interviews. The nine participants represented both native and nonnative English speakers. The participants were asked to read each item, restate it in their own words, and provide an example. The cognitive interviews provided participants opportunity to inform the researchers about the CEIP during its development by (a) clarifying the wording of each item (construct validity); (b) including appropriate examples (construct validity); (c) ensuring each item appropriately reflects the theme (construct validity); (d) ensuring item completeness (content validity); (e) eliminating redundancy (content validity); (f) ensuring the usefulness of and need for the CEIP in classroom practice (face and content validity).
Each interview lasted approximately one and a half hours and was audio recorded. Interviews were attended by at least two members of the research team, each of whom took extensive notes. Following the interview, the research team members in attendance compared and summarized their notes, and a follow-up email was sent to the entire research team. Based on the results of the cognitive interviews, the CEIP was revised. Specifically, duplicative items were removed, select items were rewritten to enhance clarity, and more practical instructional examples provided by the respondents were added.

Subsequently, the research team moved into the focus group, and field and pilot testing phases of the multi-phase development process. These efforts provided further rigor in the CEIP development leading to a tool in which the researchers were successfully able to provide (a) verification of the wording of items that are currently on the CEIP (construct validity); (b) a best example and an action item which are currently items on the CEIP (construct validity); (c) feedback on the completion process (e.g., ease, length, etc.) (usability; face validity); (d) feedback on the usefulness (e.g., useful for coaching/mentoring, useful for informing professional development etc.) (usability; face validity; construct validity); (e) data to support analysis of non-response rates and to support analysis of distribution rates; (f) a means for greater respondent debriefing. Based on this validation process, the project team established the face, content, and construct validity as well as the usability of the CEIP instrument.

Therefore, given its teacher self-assessment focus and associated reliability and validity regarding ESL instructional practices, along with the review of literature finding that no other research-based teacher ESL self-examination tool was located, the 47-item, seven-theme CEIP tool was used as the project protocol. Figure 3, below, illustrates Theme 1 of the CEIP, which is provided to illustrate the format and structure of the tool. Each of the remaining themes adheres to a similar structure and format. Instructions and rating scale are also provided to allow the reader to grasp a more complete understanding of the tool and its defined purpose and uses. 
Educator:

School:

Grade Level:

Date:

Overview: CEIP contains 47 research-based English as a Second Language (ESL) instructional practices grouped within seven essential thematic qualities for providing English learners (ELs) culturally and linguistically responsive instruction.

Purpose: CEIP is a self-assessment tool for use when educating English learners (ELs), also referred to as Emerging Bilinguals (EBs), in reading, writing, mathematics, and the social sciences. Through self-examination, educators are empowered to improve instruction by using results to: 1) Confirm/adjust high quality Tier 1 and 2 instruction; 2) Inform coaching; and 3) Clarify professional development topics.

\section{The CEIP is completed relative to delivery of an instructional unit of your choice (Check One):}

Disciplinary Unit (e.g., reading, writing, mathematics, science, social studies)

Interdisciplinary Unit (e.g., literacy, mathematics/science)

Transdisciplinary Unit (e.g., central topic/theme, unifying issue or topic of inquiry)

Title/Topic of Instructional Unit: Number of Lessons in Unit: Number of Weeks to Complete Unit:

Instructions: Circle the level to indicate the extent to which each instructional practice is incorporated in your Instructional Unit:

$4=$ Extensive (E) - Practice employed throughout all lessons in the entire Unit/Topic

$3=$ Frequent $(\mathrm{F})$ - Practice employed throughout most lessons in Unit/Topic (i.e., more than half)

$2=$ Partial (P)-Practice employed in few lessons in Unit/Topic (i.e., more than 2, less than half)

$1=$ Minimal (M)-Practice never or infrequently employed in the Unit/Topic (i.e., only 1 or 2 lessons)

\section{Theme 1: Connections}

Rate extent to which your instruction unit reinforces English Learners' connections of new content/skills to known skills by...

\section{P F E}

a. facilitating verbal discussions/brainstorming $\begin{array}{llll}1 & 2 & 3 & 4\end{array}$

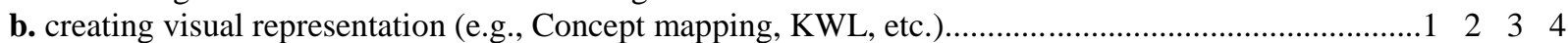

c. creating opportunities for Paired Learning/Cooperative Sharing..................................................... $12 \begin{array}{lll}2 & 3 & 4\end{array}$

d. connecting to shared school and community experiences(e.g., text to self, link learning from a task or activity completed previously to a new task to be completed, etc.) ………..............................1 $22 \quad 3 \quad 4$

e. facilitating access to previously acquired knowledge and skills ......................................................1 $2 \begin{array}{llll}2 & 3 & 4\end{array}$

Theme Score:

(Total divided by 5 )

Figure 3. Core ESL instructional practices guide (CEIP) Theme 1: Connections. Reprinted from "Core ESL instructional practices (CEIP)”. J. J. Hoover, S. Hopewell, J. Sarris (2014). Reprinted by permission.

To further illustrate essential features of the CEIP, we describe two ESL instructional items per theme.

\section{Selected CEIP Guide Items}

Theme 1: Connections

1. Connecting to shared school and community experiences (e.g., text-to-self, link learning from a task or activity completed previously to a new task to be completed, etc.).

2. Facilitating access to previously acquired knowledge and skills.

Theme 2: Relevance

1. Delivering instruction that validates learners' backgrounds and experiences (e.g., funds of knowledge, diverse cultural environments, learning preferences, heritage, and customs).

2. Using students' own interests to build learning engagement and interactions (e.g., histories and experiences relevant to content being taught; study of personally relevant cultural events or figures).

Theme 3: Native Language Utilization

1. Acquire knowledge and skills while learning in English by restating an idea or concept in native language.

2. Support vocabulary development through learning of word meanings (e.g., give an example of a synonym or antonym in native language to support understanding of concept, phonemic awareness, phonics, and math reasoning).

Theme 4: English Language Development 
1. Posting a variety of language supports (e.g., sentences stems, language frames, word walls, etc.) in the classroom to scaffold oral and written participation.

2. Accepting varied levels of responses for students acquiring English as a second language (e.g., approximations to correct responses, multiple attempts to be successful, etc.).

Theme 5: Materials

1. Build students' shared understanding of concepts and skills (e.g., materials respect students' cultural teachings, teachers capture student conversations on chart paper).

2. Examine abstract concepts in concrete ways (e.g., simulation, graphic aids, graphic organizers, meaning of manipulatives, etc.).

Theme 6: Differentiations

1. Use multiple forms of instruction (e.g., Scaffolded instruction, Sheltered Instruction, Direct Instruction, Hands-on, Modeling, Read Aloud, etc.).

2. Teach toward both language and content objectives.

Theme 7: Using Assessment to Inform Instruction

1. Adjust teaching of content/skills based on student responses obtained during daily classroom activities (e.g., listening to student discussions in a small group; observing a student completing work).

2. Adjust teaching of language development using results from planned assessment tasks completed by all students.

\section{Professional Development}

The professional development structure in the project included (a) delivery of four workshop sessions; (b) development of four action items; (c) four classroom observations, and completion of four formal interview sessions. Each two-hour workshop provided for participant debriefing from classroom implementation of action items generated from previous workshop, and provided for the presentation of additional CEIP themes based on the selfassessment, which resulted in new action items. Two themes were addressed in each workshop. Each educator generated one action item during each workshop, leading to the four classroom observations. Debriefings, which included interviews, occurred during the subsequent workshop and upon completion of the classroom observations.

\section{Findings}

The data were coded based on purpose and measure. The CEIP yielded 1-4 scores and are reported as quantitative data with reference to rank order. The qualitative observation information was generated as narrative summaries based on anecdotal records and summarized using thematic analysis, specifically within each of the seven CEIP Themes. The interviews relied on a semi-structured process in which several open-ended questions concerning use of the CEIP in action planning, classroom instruction and personal growth were asked. Thematic analysis was also employed with interview results and reported accordingly.

The process began with teacher self-assessment followed by the rank ordering of their ratings as shown in Table 1. As shown, educator self-ratings ranged from 2.42 to 3.05 , indicating that participants perceived the themes to be currently implemented partially to frequently in the delivery of their instruction to ELs

Based on the self-rating results, the two lowest rated themes were initially selected for further

Table 1

Mean Scores of Self-Assessed Themes in Rank Order

$\begin{array}{lll}\text { Theme } & \text { Mean Value } & \text { Rank (Lowest to Highest) } \\ \text { Relevance } & 2.42 & 7 \text { of } 7 \text { (Partial) } \\ \text { Native Language Utilization } & 2.48 & 6 \text { of } 7 \text { (Partial) } \\ \text { Linking Assessment to Instruction } & 2.55 & 5 \text { of } 7 \text { (Partial-Frequent) } \\ \text { Materials } & 2.60 & 4 \text { of } 7 \text { (Partial-Frequent) } \\ \text { Differentiations } & 2.93 & 3 \text {. of 7 (Frequent) } \\ \text { Connections } & 2.98 & 2 \text { of 7 (Frequent) } \\ \text { English Language Development } & 3.05 & 1 \text { of 7 (Frequent) }\end{array}$

support through workshop sessions, action items, observations, follow-up workshop sessions and debriefing interviews. Table 2 provides a summary overview of the key components addressed for each theme beginning with the two lowest rated themes. As shown, for each of the two lowest self-rated 
themes the same specific types of support and training occurred. Upon completion of the workshop and classroom observation a debriefing session with the staff occurred for each theme. Similar supports were provided for each of the other CEIP Themes based on low-high self-ratings.

Effectiveness of the piloted process on use of ESL instructional practices was determined through evidence gathered by the researches in four areas: (a) Usefulness of Self-Assessment Tool; (b) Action Items; (c) Classroom Observations; (d) Participant Interviews and Feedback. Findings associated with each of these four areas are summarized below beginning with usefulness of self-assessment using the CEIP tool.

Table 2

ESL Improvement Supports for Two Lowest Rated Themes

\begin{tabular}{ll}
\hline Theme & Workshop Topic \\
Relevance & ESL teaching practices \\
that build engagement, & motivation, and self- \\
& efficacy within a relevant \\
& learning context reflective \\
& of students' cultural \\
& teachings and background \\
& (Gay, 2010).
\end{tabular}

Native Language Utilization

Action Item Focus
ESL instructional
practices that blend
cultural perspectives with
learning tasks and
outcomes

Teacher practices that help learners use native language by building background knowledge and providing learning examples in both English and native language

\author{
Observation Reviews \\ Multiple examples of the \\ incorporation of cultural \\ perspectives discussed in \\ the workshop were \\ observed including: (a) \\ use of cooperative \\ learning groups; (b) \\ discussions about the \\ history of struggles with \\ equality; (c) defining \\ symbols or \\ representations reflective \\ of various cultures \\ Multiple examples \\ observed of use of native \\ language in the classroom \\ instruction discussed at \\ the workshop included: \\ (a) instructions delivered \\ in both English and \\ Spanish; (b) use of mixed \\ language groupings \\ during a math activity; (c) \\ discussing math activity; \\ (d) discussing the \\ meaning of a Fable in \\ both English and Spanish
}

\section{Usefulness of a Self-Assessment Tool}

The CEIP self-assessment tool takes approximately 25 minutes to complete and may be completed in one or two settings. To complete the guide, educators reflect on current practice prompted through each item and record current perception of its use in the teaching of English learners in the classroom. Therefore, a most critical outcome in our work was gathering evidence about the extent to which classroom teachers perceive completion of the self-ratings to be useful in their teaching. All practitioners indicated that reflecting on the ESL practices through self-completion of the tool was useful to them as teachers. Several representative statements expressed by educators describe the findings pertaining to the usefulness of the selfassessment tool to inform classroom instruction include:

- "It's always good to see what you can improve on -- I realized that my parent involvement is weaker this year than in the past. "

- "It shows specific areas to consider."

- "This will benefit grade level team discussions about quality of general classroom instruction for ELs." 
- "Completing the self-assessment guide has made me realize that I focus a lot more on content than language."

- "Clearly identifies weaknesses to turn into instructional goals."

- "Helps me identify what I am doing well and what I need to work on."

- "The self-assessment guide challenges me to examine my teaching."

- "Items on the guide will be of great benefit in helping develop our school-wide professional development on the topic of teaching ELs."

- "Instructional themes reflect what we should be addressing in our teaching, and this guide will help us monitor that we include each theme during instruction."

- "Self-assessment based on the guide helps us determine what we are doing and not doing, thereby providing a structure to develop action items for instructional improvement."

These and similar feedback items from participants indicate important findings about the perceived value of self-assessment in professional development and instructional adjustments.

\section{Action Items}

A second indicator reflecting the value of this process and use of self-assessment is seen in the different types of action items developed by participants for the themes. For purposes of this project, an Action Item was characterized as a specific skill or best practice stated in general terms for which the educator wished to improve or begin to use. These action items, in turn, were incorporated into the lesson and unit plans to be operationalized. Table 2 described the focus of the action items for two targeted self-assessment themes. Additional specific representative action items included in the findings are: (a) Increase my attention to wait time; (b) Include cultural figures to provide context; (c) Plan for more shared learning time; (d) Scaffold with more graphic organizers and sentence stems; (e) Increase my frontloading of vocabulary; (f) Use more rubrics in my lessons; (g) Use more frequent assessments rather than just those at mid/end of unit; and; (h) Increase instructional connections to sociocultural experiences. These and similar action items provided educators specific ideas for implementing the workshop theme coverage into daily classroom instruction.

\section{Classroom Observations}

Though the initial perspectives about ESL practices documented by the participants were based on self-assessment, it is important to corroborate these perspectives once action items are identified to record independent evidence. Therefore, a key component in the process is to conduct classroom observations. The CEIP Themes were presented in four separate workshops with classroom observations following each session. Each classroom teacher in the pilot project was observed once by one of the project researchers as a follow-up to the workshop sessions. The primary purpose of the classroom observation was to determine whether the action item generated by the teacher was evident in the classroom instruction. The observation occurred 3-4 weeks after the action item was developed to allow teachers time to incorporate into their instruction. The observation was semi-structured with the observer recording in narrative form observed teacher and student behaviors relative to the action item. Overall, the classroom observations yielded project findings that supported the workshop process and participant growth in using research-based ESL instructional practices in several ways, as illustrated below.

\section{Participant Observation Findings by CEIP Theme}

Theme 1: Connections

Teachers were observed making consistent connections to prior learning, facilitating brainstorming and connecting discourse, and connections to students' own lives (e.g. baking at home).

Theme 2: Relevance

Teachers demonstrated different problemsolving strategies to the students, allowing them to choose strategy they would use.

Theme 3: Native Language Utilization

Teachers used students' first language periodically consistent with their own abilities in the first language which varied by classroom teacher (e.g. “Como se dice en español?”).

Theme 4: English Language Development

Teachers demonstrated skill at accepting and validating responses that were partially correct from English learners, which is essential for students in early stages of English language development.

Theme 5: Materials

Teachers were observed using students' own drawings as a springboard for probing and 
questioning for deeper meaning: "Can you tell me a little more about that?"

\section{Theme 6: Differentiations}

An observed example of differentiation to accommodate language skills and objectives the teacher assigned roles based on level of English skills during a story enactment in a Reader's Theater activity.

Theme 7: Assessment to Inform Instruction Students were shown a video that modeled an effective presentation, followed by having students prepare a first draft of their own presentations, to which timely formative feedback was provided.

\section{Participant Interviews and Debriefing}

An important fourth source of evidence illustrating the positive effects obtained through implementation of this project is found in the evaluative feedback gathered through semi-structured interviews and follow-up workshop debriefing sessions. On several occasions throughout the project, participants' input was gathered to determine extent to which the tasks and activities were meeting both their professional development and personal growth needs in acquiring and using contemporary ESL instructional practices. Each participant was interviewed as a component of the observation session and during subsequent workshop sessions.

Four types of interview questions about instruction and the CEIP were asked following the observations:

1. What are your impressions about the usefulness of the CEIP in your teaching?

2. Did you experience any problems or issues completing the CEIP?

3. Did you experience any issues identifying an Action Item for any of the Themes?

4. How did completion of the CEIP inform existing instructional practices with ELs?

Also, during workshop debriefing, participants responded to three general instructional items:

1. What are your impressions about the completed CEIPs?

2. What are your impressions about the identified Action Items?

3. Do you envision classroom instruction for ELs being improved through use of the CEIP?

Participant input gathered through the interviews and debriefing sessions was analyzed using thematic analysis to identify common themes among responses. Similar to the classroom observations, the interview findings are summarized by theme, illustrated below.

\section{Participant Observation Findings by CEIP Theme}

Theme 1: Connections

Teachers stated that they recognized that vocabulary was a major concern, and that they intended to front-load and repeat/recycle vocabulary throughout their instruction.

Theme 2: Relevance

Teachers reported to be more mindful and intentional with their pairing and grouping of students to take into account English language skills in addition to content knowledge.

Theme 3: Native Language Utilization

Teachers suggested that more supports in the classrooms, such as word walls, sentence frames, and connections between students' L1 and L2 would build student confidence and improve learning. Theme 4: English Language Development

Teachers stated that they became more mindful and intentional of their practices to ensure that English language development is addressed.

Theme 5: Materials

Teachers indicated that they planned to use more visuals in teaching abstract concepts and vocabulary.

Theme 6: Differentiations

Teachers stated that they began to include greater emphasis on language objectives (e.g., use more sentence frames), in addition to content objectives to support English learners.

Theme 7: Assessment to Inform Instruction

Teachers expressed that they now understand how students would be better able to "show what they know" during formative and summative assessments.

As shown, interview responses were highly positive and supportive of educator growth in the inclusion of acquired ESL practices in teaching and learning.

Participants were also asked to reflect on how they saw their EL students benefiting from the selfassessment and associated professional supports provided via the piloted process. Selected representative educator statements reflecting findings from this project include

- "Opportunity to demonstrate their capabilities." 
- "Speaking in either language is easier with supports that build confidence."

- "Students are using, asking to use, and recognize strategies we've used in the past."

- "Learners experience more clarity, less stress, and are more engaged during instruction."

- "Students are provided increased opportunities to understand academic vocabulary in order to access content standards."

- "Both language and cultural needs will be met."

- "Students are better able to help each other learn vocabulary necessary to be successful in learning."

\section{Discussion}

The research question that guided this study is: What effect does a professional development process, grounded in educator self-assessment, have on identifying and improving use of ESL instructional practices when teaching ELs in a rural school setting? The process piloted in this study assisted teachers in a rural county elementary school to increase their knowledge of ESL best practices, initially through self-assessment, followed by workshop and classroom observation support. Several important items warrant discussion relative to the research question based on project findings.

\section{Usefulness of CEIP Tool}

As captured in the statements presented above made by the school staff after completion of the selfassessment tool, the research goal of facilitating one's own consideration of current teaching was achieved. Additionally, the balanced ratings reflected in the range of mean scores shown in Table 4 suggest that thoughtful consideration went into completion of the self-assessment (McCombs, 2003; Ross \& Bruce, 2007). No theme was rated extremely high suggesting an honest appraisal of the current status in the overall use of ESL instructional practices in the rural county elementary school. Additionally, educators expressed appreciation for the opportunity to examine own teaching in a more personal and nonthreatening way as facilitated through the CEIP tool. These findings support previous research on effective uses of self-assessment as one viable process within a comprehensive educator professional development system (Schmidt et al., 2009).

\section{Action Items}

The different action items documented by the educators reflect practices associated with the targeted seven themes (e.g., Differentiations, Relevance, Native Language Utilization, etc.). Critical to this project and of most importance is that action items were generated by educators themselves, reflecting their commitments to improve teaching and learning for ELs, rather than being imposed by school administration or outside sources. Additionally, the action items reflect research-based instruction, expanding educators' toolkits of contemporary ESL instructional practices. The variety of action items documented and implemented represented many of the best practices identified through research located on the CEIP. The debriefing sessions allowed both grade level team members and the school staff as a collective whole to learn about, discuss, and add to their own toolkit of ESL best practices. Overall, the project supports prior research results describing the value of action items to facilitate increased use of best practices in teaching and learning generated through self-assessment and examined through relevant workshop sessions (Lupinski, Jenkins, Beard, \& Jones, 2012; Ross \& Bruce, 2007).

\section{Classroom Observations and Interviews}

An important feature of this project was facilitating teacher development and articulation of action items followed by classroom observations conducted by members of the project team. These observations, and associated interviews, ensured that the teachers were implementing their action items effectively in their own classrooms, which is essential to workshop success (Borko, 2004; Cornett \& Knight, 2009). In the process of implementing action items teachers were observed incorporating multiple themes from the CEIP simultaneously. For example, in many classroom situations teachers were observed implementing intentional grouping of students, reinforcement of vocabulary in various ways, and multiple opportunities for students to learn content and develop English language skills. Specifically, the classroom observations (a) validated the connection to the initial three steps in the ESL instructional improvement model (self-assessment, thematic workshop session, action item development); (b) provided evidence of the workshop-to-classroom carry-over of developed action items; (c) demonstrated connections between self-assessments and changes in classroom instructional practices, and; (d) validated classroom teachers' self-improvement efforts empowering them to continue in the piloted improvement process. 
In regard to interview implications, teachers overwhelmingly described multiple ways the CEIP tool practices had been or will be incorporated into instruction for ELs. This included describing some of the same features seen during the observations such as intentional grouping, paired learning, word walls, vocabulary development, and connections to prior learning. Project educators clearly articulated highly relevant uses of the CEIP tool reflecting numerous best practices consistent with current literature (e.g., Kretlow \& Bartholomew, 2010; Knight, 2012). Overall, based on the interconnected tasks of action item development, classroom observations, and interviews/debriefing, several common ESL practices discussed during the delivery of the ESL Instructional Improvement Process were evident showing promise for continuation beyond this project:

Language objectives. Teacher expressed confidence that additional language objectives along with content objectives will be developed and incorporated into daily instruction.

Visuals. Additional use of visuals and sentence frames are to be included in classroom instruction as well.

Vocabulary. Teachers expressed that as a result of this project they have an increased appreciation of the importance of knowing the vocabulary that EL students might not know, and use more strategies to address these vocabulary concerns.

Strategies. An increased awareness of weaving more ESL strategies into various aspects of the school curriculum is expected as a result of this project.

In summary, educators felt empowered in that they became more mindful of effective ESL instructional practices. Additionally, participants indicated that their ESL instructional practices are changing by identifying and selecting more appropriate practices to meet ELs' content and language needs, rather than only content objectives.

Making certain that general education for ELs is grounded in the delivery of core ESL practices assists in framing cultural and linguistic responsive teaching. Results from this study support related research that shows that a professional development structure, grounded in self-assessment of instructional uses of essential ESL practices, facilitates teachers' (a) confirmation of existing practice; (b) development of action items to improve upon existing practice; (c) implementation of developed action items in classroom instruction of ELs. This aligns with Lupinksi et al. (2012) who wrote that reflection on practice has powerful impacts on teaching.

This project also supported efforts to address two important rural county educator preparation challenges regarding specific efforts to increase knowledge of contemporary best practices, and relevant and timely professional development. The process implemented in this research represents a promising framework to address both need areas. Responding to their overall experiences, the continuum of: (a) self-assessment; (b) thematic workshop sessions; (c) action item development; (d) classroom observations/interviews proved effective in advancing teacher use of ESL classroom instructional practices for educating ELs in a rural county elementary school.

\section{Limitations and Recommendations}

This pilot study was limited to one elementary school in a mountain west rural county school district. Results are to be interpreted within the parameters of a piloted process particularly as they pertain to rural schools. Additionally, the project examined one process for professional development that was planned and implemented through a collaborative partnership. The influence of the partnership contributed to the successful implementation of the project. Similar results may not be achieved in less developed university-school district partnerships.

Additional research completed in other rural county schools is necessary to confirm the positive results found through this project, including use of the ESL Instructional Improvement Process.

Specifically, the process of self-assessment, thematic workshop sessions, action item development, and classroom observations/interviews to increase use of ESL instructional practices requires replication and additional study to further document effectiveness at improving classroom teaching of ELs in rural county elementary schools. The ESL Instructional Improvement Process discussed in this article shows promise as an effective and low-cost means for rural teachers to advance their instruction of English learners using the research-based CEIP tool, available at no cost at http://buenocenter.org/welcome/materials/. Several recommendations supported by project findings within the potential limitations are provided to advance research to practice in the professional development of educators in rural schools for work with English learners:

1. Employ a dynamic professional development process that includes educator input in its development and implementation.

2. Structure the initial workshop sessions around educator self-assessment to begin 
coverage of topics most relevant to participants.

3. Conclude each workshop with the development of teacher generated action items with defined plans for follow-up classroom observations.

4. Provide teachers 2-3 school weeks to implement the action items prior to the classroom observation, allowing them time to ease into incorporating into existing instructional structures.
5. Guide educator discussions and examination of the importance of incorporating CEIP instructional themes to provide English learners sufficient opportunities to learn.

6. Provide participants opportunities to debrief among themselves to share experiences, challenges and success in the implementation of action items, prior to moving into the subsequent workshop theme or topic.

\section{References}

Arnold, M. L., Newman, J. H., Gaddy, B. B., \& Dean, C. B. (2005). A look at the condition of rural education research: Setting a direction for future research. Journal of Research in Rural Education, 20(6).

August, D., Shanahan, L., \& Shanahan, T. (2006). Developing literacy in second-language learners: Lessons from the Report of the National Literacy Panel on language minority children and youth. New York, NY: Routledge.

Avalos, B. 2011. Teacher professional development in Teaching and Teacher Education over ten years. Teaching and Teacher Education 27(1), 10-20.

Basil, A. I. (2011). Teacher satisfaction with professional development in rural elementary schools in New York State. ProQuest Dissertations and Theses, 3454671.

Borko, H. (2004) "Professional Development and Teacher Learning: Mapping the Terrain." Educational Researcher 33, no. 8. 3-15.

Brown, J. E., \& Doolittle, J. (2008). A cultural, linguistic, and ecological framework for response to intervention with English language learners. Teaching Exceptional Children, 40(5), 67-72.

Burton, M., \& Johnson, A. S. (2010). "Where else would we teach?": Portraits of two teachers in the rural South. Journal of Teacher Education, 61(4), 376-386.

Cason, M. G. (2011). Activating Prior Knowledge With Cues and Questions As a Key Instructional Strategy to Increase Student Achievement in Low Socioeconomic Middle Schools. Dissertation, UMI 3469058. Ann Arbor, MJ: ProQuest.

Choi, Y. (2013). Teaching Social Studies for Newcomer English Language Learners: Toward Culturally Relevant Pedagogy. Multicultural Perspectives, 15(1), 12-18.

Cizek, G. J. (2010). An introduction to formative assessment: History, characteristics, and challenges. In H. Andrade \& G. Cizek, (eds.) Handbook of formative assessment (pp. 3-17). New York: Taylor and Francis.

Clarke, S., \& Wildy, H. (2011). Improving the small rural or remote school: The role of the district. Australian Journal of Education (55)(1), 24-36.

Cornett, J., \& Knight, J. (2009). Research on coaching. Coaching: Approaches and perspectives, 192-216.

Creswell, J. W. (2011). Educational research: Planning, conducting, and evaluating quantitative and qualitative research (4th $\mathrm{Ed}$.). Boston, MA: Pearson.

Dunn, M. W., Cole, C. M., \& Estrage, A. (2009). Referral Criteria for Special Education: General Education Teachers' Perspectives in Canada and the United States of America. Rural Special Education Quarterly, Vol. 28, No. 1.

Garcia, S. B., \& Ortiz, A. A. (2006). Preventing disproportionate representation: Culturally and linguistically responsive prereferralv interventions. (NCCRESt Brief). Tempe, AZ: National Center for Culturally Responsive Educational Systems.

Gay, G. (2010). Culturally Responsive Teaching: Theory, Research, and Practice. New York: Teachers College Press

Glesne, C. (2005). Becoming qualitative researchers: An introduction ( $3^{\text {rd }}$ ed.). Boston: Pearson Allyn \& Bacon.

Goldenberg, C. (2008). Teaching English language learners: What the research does - and does not - say. American Educator, 8-44.

Gutierrez, K., \& Rogoff, B. (2003). Cultural ways of learning: Individual traits or repertoires of practice. Educational Researcher, 32, 19-25.

Herrera, S. G., \& Murry, K. G. (2005). Mastering ESL and bilingual methods: Differentiated instruction for culturally and linguistically diverse (CLD) students. Boston, MA: Pearson Allyn and Bacon. 
Hoover, J. J., Hopewell, S. \& Sarris, J. (2014). Core ESL instructional practices (CEIP). Boulder, CO: BUENO Center, University of Colorado.

Hoover, J. J. Klingner, J., Baca, L. M. \& Patton, J. M. (2008). Methods for teaching culturally and linguistically diverse exceptional learners. Columbus: Pearson.

Hopewell, S. 2011. Leveraging bilingualism to accelerate English reading comprehension. International Journal of Bilingual Education and Bilingualism, 14 (5), 603-620.

Kindler, A. (2002). Survey of the states' limited English proficient students and available educational programs and services 2000-2001 summary report. Washington, DC: National Clearinghouse for English Language Acquisition.

Klingner, J. K., Soltero-Gonzalez, L., \& Lesaux, N. (2010). Response to intervention for English language learners. In M. Lipson \& K. Wixson (Eds.), Successful approaches to response to intervention (RTI): Collaborative practices for improving K-12 literacy (pp. 134162). Newark, DE: International Reading Association.

Knight, J. (2012). Coaching to improve teaching: Using the instructional coaching model. In van Nieuwerburgh, C. (ed.) Coaching in Education: Getting Better Results for Students, Educators, and Parents (p. 93 -114). London: Karnac Books Ltd.

Kretlow, A. G., \& Bartholomew, C. G. (2010). Using coaching to improve the fidelity of evidencebased practices: A review of studies. Teacher Education and Special Education, 33(4), 279299.

Kretlow, Allison G., Cooke, Nancy L., \& Wood, Charles L. (2011). Using In-Service and Coaching to Increase Teachers' Accurate Use of Research-Based Strategies. Remedial and Special Education, 33, 348-361.

Ladson-Billings, G. 2001. Crossing Over to Canaan: The Journey of New Teachers in Diverse Classrooms. San Francisco: Jossey-Bass.

Ladson-Billings, G. (1994). The dreamkeepers: Successful teachers of African American children. San Francisco, CA: Jossey-Bass.

Lupinski, K., Jenkins, P., Beard, A., \& Jones, L. (2012). Reflective Practice in Teacher Education Programs at a HBCU. Educational Foundations, Summer-Fall, 81-92.

McCombs, B. L. (2003). A framework for the redesign of $\mathrm{K}-12$ education in the context of current educational reform. Theory into Practice, 42(2), 93-101.
Ortiz, A. A., \& Artiles, A. J. (2010). Meeting the needs of ELLs with disabilities: A linguistically and culturally responsive model. In G. Li and R. A. Edwards (eds.) Best practices in ELL instruction (pp. 247-272). New York: Guilford Press.

O’Toole, J. E. (2010). Language-learning experiences as a source of personal practical knowledge for general classroom teachers of English language learners. Ann Arbor, MI: ProQuest. Dissertation UMI 3437582.

Robinson, G. R., Bursuck, W. D., \& Sinclair, K. D. (2013). Implementing RTI in Two Rural Elementary Schools: Encouraging Beginnings and Challenges for the Future. The Rural Educator, 34(3), 1-9.

Ross, J. A., \& Bruce, C. D. (2007). Teacher selfassessment: A mechanism for facilitating professional growth. Teaching and Teacher Education, 23, (2), 146-159.

Ruiz-Primo, M. A., \& Furtak, E. M. (2007). Exploring teachers' informal formative assessment practices and students understanding in the context of scientific inquiry. Journal of Research in Science Teaching 44(1), 57-84.

Saunders, W., Goldenberg, C., \& Marcelletti, D. (2013). English Language Development: Guidelines for instruction. American Educator, 13.

Schmidt, D. A., Baran, E., Thompson, A. D., Koehler, M. J., Mishra, P., \& Shin, T. (2009). Technological pedagogical content knowledge (TPACK): The development and validation of an assessment instrument for pre-service teachers. Journal of Research on Technology in Education, 42(2), 123-149.

Sorrells, A. M., Webb-Johnson, G., \& Townsend, B. L. (2004). Multicultural perspectives in special education: A call for responsibility in research, practice, and teacher preparation. In S. M. Sorrells, J. H. Reith, \& P. T. Sindelar (Eds.), Critical issues in special education (pp. 73-91). Boston, MA: Pearson Education.

Stockard, J. (2011). Increasing reading skills in rural areas: An analysis of three school districts. Journal of Research in Rural Education, 26(8), 1-19.

Teemant, A. (2013). A mixed methods investigation of instructional coaching: Understanding teacher transformation and sustainability. Urban Education, April 22, 2013, doi: 10.1177/0042085913481362, On-line.

Tharp, R. G., Doherty, R. W., Echevarria, J., Estrada, P., Goldenberg, C., \& Hilberg, R. S. (2004). Five Standards for Effective Pedagogy and 
Student Outcomes (No. G1). Berkeley, CA: University of California, Berkeley.

Valle, M. S., Waxman, H. C., Diaz, Z., \& Padrón, Y. N. (2013). Classroom Instruction and the Mathematics Achievement of Non-English Learners and English Learners. The Journal of Educational Research, 106(3), 173-182.

Wenger, K. J., \& Dinsmore, J. (2005). Preparing rural preservice teachers for diversity. Journal of Research in Rural Education, 20(10). 1-15.

Wenger, K. J., Dinsmore, J., \& Villagómez, A. (2012). Teacher identity in a multicultural rural school: Lessons learned at Vista Charter.

Journal of Research in Rural Education, 27(5). Zainuddin, H., Yahya, N., Morales-Jones, C. A., \& Ariza, E. N. (2011). Fundamentals of teaching English to speakers of other languages in k-12 mainstream classrooms. (3rd ed., pp. 173 192). United States: Kendall Hunt Publishing Company. 
About the authors:

John J. Hoover, Ph.D. is Associate Professor (Research) in the School of Education at the University of Colorado at Boulder. His research and teaching interests address the education of diverse learners and their teachers in rural and urban school systems in the areas of special education referral and assessment of diverse learners, multi-tiered support systems (MTSS), and IEP development and implementation. He is Principal Investigator of a model demonstration project developing and implementing RTI for ELs in rural school system.

Julia Sarris, Ph.D. obtained a PhD in Education and an MA in Linguistics/TESOL from the University of Colorado at Boulder. She has taught ESL for over a decade, and has developed and presented classes and workshops to both in-service and pre-service teachers of English learners.

Raymond Hill, Ph.D. is a Research Associate in the BUENO Center in the School of Education at the University of Colorado at Boulder. He directs graduate level teacher education programs in second language and special education for students in the pre $\mathrm{K}-12$ grades. 